\title{
Excavaciones arqueológicas en la Casa Bodega y Quadra en el Centro Histórico de Lima
}

\author{
Miguel Fhon ${ }^{a}$
}

\begin{abstract}
Resumen
El presente artículo abordará los principales resultados de las excavaciones arqueológicas realizadas en la Casa Bodega y Quadra, que ponen en evidencia una serie de estructuras ubicadas bajo el nivel actual de la casa, bajo gruesas capas de relleno. La investigación arqueológica brindó la información necesaria para determinar el motivo por el cual estos espacios fueron cubiertos y vincular estos sucesos con el gran terremoto que sufrió la ciudad de Lima durante el año de 1746. Por otro lado, las estructuras descubiertas, al ser contrastadas con el dato histórico, demostraron una variación del espacio, que pasa de lo público a lo doméstico; todo ello, relacionado directamente con la evolución de la traza urbana de Lima virreinal.
\end{abstract}

Palabras clave: excavaciones, relleno constructivo, terremoto, estructuras arquitectónicas, urbanismo

\section{Abstract}

\section{ARCHAEOLOGICAL EXCAVATIONS AT CASA BODEGA Y QUADRA, LIMA HISTORIC DOWNTOWN}

This article addresses the principal results of the archaeological excavations at the Casa Bodega y Quadra, which uncovered a series of structures beneath the modern structure located on the site, below thick layers of fill. Archaeological excavations provide evidence that these earlier layers were buried in the wake of the earthquake that devastated the city of Lima in 1746. Comparison between these earlier structures and historical data demonstrates how space within the site was transformed from public to domestic - processes directly related to the evolution of the urban layout of viceregal Lima.

Keywords: excavations, construction fill, earthquake, architectural structures, urbanism

${ }^{a}$ Museo de Sitio Bodega y Quadra, Municipalidad de Lima

Correo electrónico: mfhonb@gmail.com 


\section{Antecedentes}

Durante las últimas décadas, se ha incrementado el interés por aquellos trabajos arqueológicos que remiten a contextos de época virreinal y republicana; inicialmente, los primeros trabajos en arqueología urbana en la ciudad de Lima, pertenecientes a estratos de relleno virreinal que cubrían elementos arquitectónicos, se realizaron en 1964 en Huaca Palomino (Cárdenas 1973). Entre los materiales encontrados dentro de la acumulación de estos estratos de relleno, se destacaron fragmentos vidriados entre otros artefactos, para lo cual Cárdenas propuso una cronología aproximada de esos contextos que iban desde mediados del siglo XVI hasta inicios del siglo XVII.

Años más tarde, en 1973, dentro de la cátedra de arqueología peruana dirigida por la doctora Josefina Ramos de Cox, se realizaron excavaciones arqueológicas en la Huaca Casa Rosada. Estas intervenciones se llevaron a cabo en un contexto de relleno y en un área de acumulación de basura colonial (Arrieta et al. 1974-1975). Según las investigaciones, la ocupación española se asentó sobre un montículo prehispánico; entre los materiales, destacaban cantidades de vidrio y loza.

En el caso del Centro Histórico de Lima, son pocas las intervenciones arqueológicas para contextos de época virreinal y republicana. Al respecto, cabe destacar la investigación arqueológica realizada en la Casa Osambela-Oquendo en la década de los ańos ochenta, a cargo de la doctora Isabel Flores y el arqueólogo Rubén García (Flores, García y Huertas 1981). Las excavaciones se centraron en varios sectores de la casa y se evidenció material cultural en algunos contextos de relleno; en ese marco, destaca el hallazgo de fragmentos de cerámica vidriada, loza, vidrio y material óseo. En varias de las descripciones de estos contextos de relleno, están presentes las grandes concentraciones de fragmentos de ladrillo y tierra.

Por otro lado, es importante mencionar lo reportado por el arqueólogo Juan Mogrovejo, quien hace referencia del hallazgo de grandes estratos de basura virreinal y republicana dispuestos en distintas áreas del Centro Histórico de Lima y puestas al descubierto mediante trabajos de obras civiles (Mogrovejo 1998). Los resultados de estas investigaciones, en su mayoría, muestran la existencia de una gran cantidad de material arqueológico, entre los que se distingue principalmente la cerámica, osamentas, objetos de metal y madera. Sin embargo, los materiales con contextos definidos seguían siendo escasos; se debe considerar que algunas de las intervenciones se hicieron como consecuencia de trabajos de construcción y renovación en áreas urbanas.

Entre los ańos 2003 y 2004, la Municipalidad de Lima, a través de la Empresa Municipal Inmobiliaria de Lima (Emilima S.A.), en su afán por recuperar el Centro Histórico de Lima, a través del Programa de Renovación Urbana, se propuso intervenir una serie de inmuebles de carácter virreinal y republicano como parte de un proyecto de gran envergadura. Se centraron en parte de la ladera del río Rímac, enfatizando esta intervención en la manzana del Rastro y de la Soledad, que se encuentran en el espacio que conforma el cruce del jirón Áncash con el jirón Lampa.

En dicha manzana, se realizaron diversos trabajos de puesta en valor y se recuperaron una serie de casas, entre las que se encontraba la Casa Bodega y Quadra; por sus características, se consideró necesario realizar intervenciones arqueológicas. Una primera etapa fue realizada entre los años 2005 y 2006, la cual estuvo a cargo del arqueólogo Daniel Guerrero, quien reportó estructuras subterráneas y el hallazgo de pisos empedrados y una serie de construcciones a cuatro metros de profundidad. De igual manera, fueron encontrados diversos artefactos de época virreinal y republicana, que fueron intervenidos en un cincuenta por ciento. Años más tarde, se volvieron a retomar los trabajos de investigación arqueológica; de este modo, se inició la segunda etapa realizada en el ańo 2010, mediante el Proyecto de Investigación Arqueológica y Puesta en Valor de la Casa Bodega y Quadra. En esta temporada, se continuaron los trabajos de excavación arqueológica y se dejaron al descubierto arcos, muros, pisos empedrados entre otros elementos constructivos; de igual manera, se realizó la conservación y restauración de dichas estructuras.

En los contextos de relleno que cubrían las estructuras, se fueron encontrando una serie de materiales muy diversos, como cerámica de características muy variadas, correspondiente al período virreinal y republicano, material óseo, metales, vidrio, entre otros. De este modo, la 


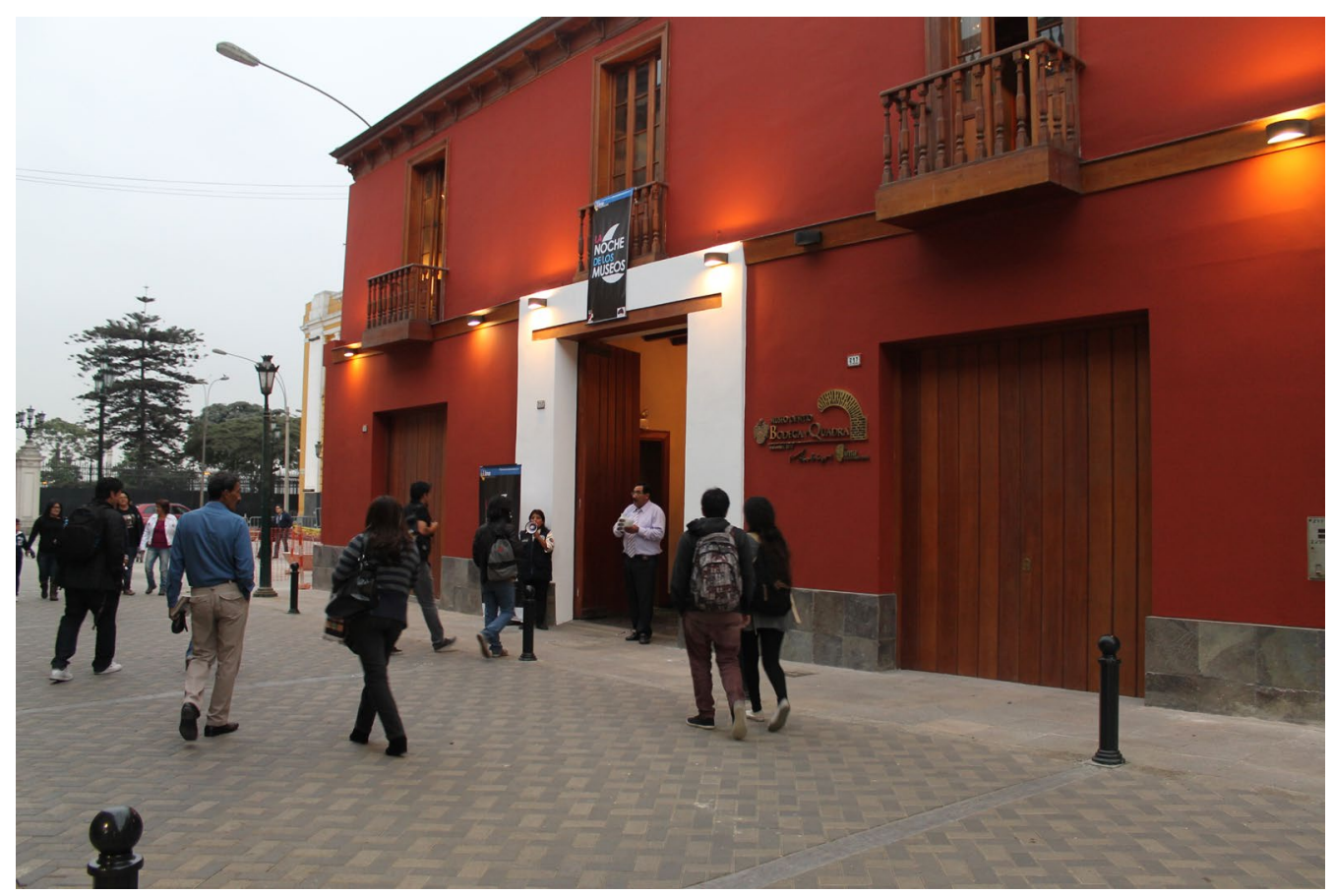

Figura 1. Vista del frontis de la Casa Bodega y Quadra (Foto por M. Fhon).

puesta en valor de la Casa Bodega y Quadra permitió iniciar los trabajos de investigación arqueológica y descubrir una serie de elementos que, sumados a la documentación histórica, nos ayudan a interpretar el modo de vida de la sociedad limeña de los siglos XVII, XVIII y XIX desde una perspectiva diferente a la documentación escrita.

\section{Escenario y diseño de la Casa Bodega y Quadra}

La Casa Bodega y Quadra se ubica dentro del centro histórico de la ciudad de Lima, en lo que se conocía antiguamente como el damero de Pizarro, exactamente en el jirón Áncash 209-213-217 (Fig. 1). Comprende el espacio desde su acceso en el jirón Áncash, por el lado sur (asentado sobre el nivel actual) hasta el muro de tajamar en su lado norte (construido a desnivel sobre la ladera del río); la casa es colindante al oeste con la antigua Estación de Desamparados y, en su lado este, con la Casa del Rastro y el Condominio de la Muralla. La casa en el sector sur posee tres vanos de acceso, y conserva la arquitectura de la primera y la segunda planta, gracias a los trabajos de conservación y restauración realizados por la Municipalidad de Lima (Fig. 2), que ha mantenido distribución típica de la construcción virreinal del siglo XVIII, con presencia de patio, zaguán, balcones, pilastras y corredores.

Los trabajos de investigación arqueológica desarrollados durante las temporadas 2005-2006 y 2010 permitieron establecer con certeza la presencia de dos sectores: el Sector Sur, referido a la casa propiamente dicha, que, como se ha mencionado, se extiende desde los accesos principales, al nivel de la calle, hasta la pendiente de la ladera del río, y el Sector Norte, correspondiente al área subterránea, con construcciones sobre la ladera del río, comprendido desde donde se inicia la ladera hasta las bases del muro de tajamar o contrafuerte del río Rímac. (Fig. 3). Las dos temporadas de investigación arqueológica se centraron en este sector por las características que presentó esta área y para responder a las interrogantes: ¿Por qué la presencia de estructuras a cuatro metros de profundidad?, ¿qué motivó el enterramiento de dichas estructuras? 


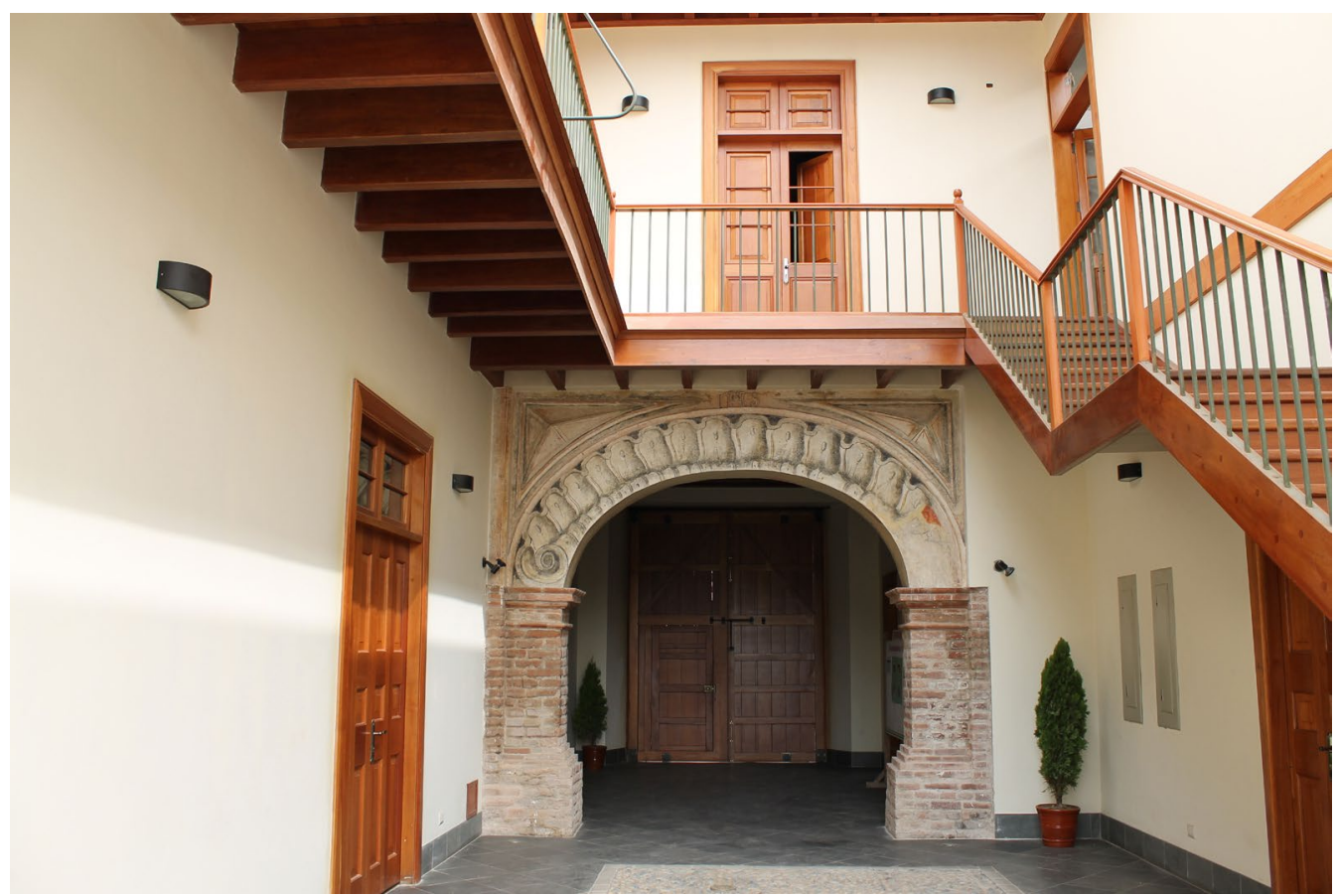

Figura 2. Vista del sector Sur de la Casa Bodega y Quadra (Foto por M. Fhon).

El Sector Norte tiene una extensión promedio de 50,63 metros de largo y 18,85 metros de ancho y una pendiente natural de 3,50 metros. Durante las primeras excavaciones arqueológicas en esta área, Guerrero logró reconocer tres arcos, dos de ellos de ladrillo y uno de adobe, muy deteriorados y a punto de colapsar. También, se descubrieron algunos recintos con pisos empedrados de canto rodado, dispuestos en bandas horizontales y verticales separados por líneas de piedra a modo de espiga ${ }^{1}$.

Posteriormente, los trabajos realizados por el Proyecto de Investigación Arqueológica y Puesta en Valor de la Casa Bodega y Quadra, en la temporada 2010, permitieron liberar las capas de relleno que aún cubrían gran parte de esta área, descubrir la existencia de varios recintos y estructuras, y definir de qué manera se conectaban cada uno de estos ambientes. Asimismo, se descubrió un pasaje y parte del Muro de Tajamar, que permanecieron cubiertas por los rellenos constructivos.

\section{La metodología aplicada en las labores de campo y gabinete}

Las labores de excavación en el Sector Norte (Plataforma 2) se realizaron previa cuadriculación general del área a fin de obtener un registro gráfico con coordenadas cartesianas. Las cuadrículas fueron conformadas en unidades de cinco por cinco metros. Estas cuadrículas tuvieron una orientación basada en los ejes norte-sur y este-oeste. Las excavaciones se realizaron a través de unidades arquitectónicas; es decir, cada ambiente se consideró como una unidad de excavación.

El registro de capas, el cual tuvo una denominación alfabética, se realizó definiendo las dimensiones de cada estrato o deposición basándose en las características de color, consistencia y composición. Para la remoción de los depósitos de tierra o capas, se tuvo en cuenta niveles arbitrarios de 25 centímetros, usados, por ejemplo, en anchos horizontes o estratos que definían depósitos o capas amplias. Por su parte, el registro escrito se realizó a través de anotaciones y se emplearon fichas de capas, de contexto, de hallazgos, entre otros. El registro general de campo se llevó a cabo de un modo estándar, que incluyó tomas de planta y perfil luego de la limpieza 


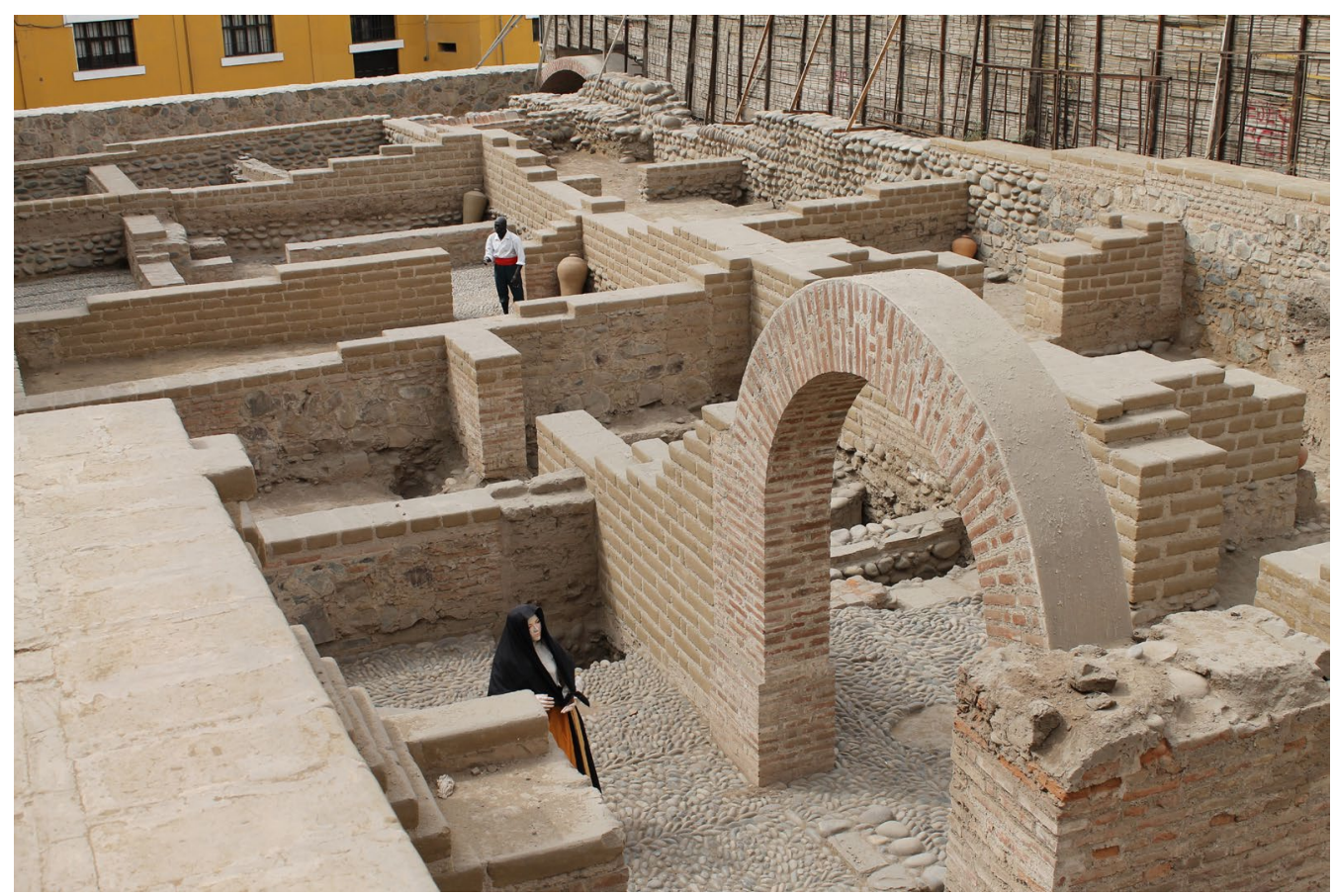

Figura 3. Vista del sector Norte de la Casa Bodega y Quadra (Foto por EMILIMA S.A. - Municipalidad Metropolitana de Lima).

y excavación de cada una de las unidades. Todos los gráficos fueron representados con datos completos: título (perfil, corte, elevación, planta, etc.), precisión de la vista, norte, oeste, de acuerdo a las características de los registros. Los dibujos se realizaron en escala 1:20 para los dibujos de planta, 1:50 para los dibujos de corte y los planos generales en 1:100.

El material arqueológico producto de las intervenciones arqueológicas fue trabajado de forma paralela durante el proceso de excavación. En función de ello, se realizaron ambas actividades: campo y gabinete a la vez, lo que permitió avanzar de manera conjunta estas actividades en el proceso de registro y la recopilación de información. Los materiales arqueológicos procedentes de las excavaciones fueron clasificados por su tipología en cerámica, restos óseos, material orgánico, artefactos, metales, etc., y, a la vez, subdivididos por categorías, como en el caso de la cerámica: porcelana, cerámica vidriada, loza, entre otros. El inventario de los materiales se consolidó en una base de datos, que permitió identificar las piezas en las cajas ya almacenadas, mediante un listado con las descripciones de cada material. Para la realización del Inventario de Gabinete, se consideraron los siguientes criterios. Primero, se tomó en cuenta el recinto, que fue nuestra principal variable de ordenamiento. Segundo, se procedió a ordenar por capa y nivel, y, tercero, el tipo de material al que correspondía cada bolsa. Luego de estas tres variables de clasificación, se procedió con el llenado de las hojas de inventario, asignándosele a cada una de las bolsas un número de registro y la caja a la que pertenece. El número de caja dependió del tipo de material al que correspondía.

\section{El proceso de análisis de los materiales encontrados en los contextos de relleno}

Se trabajó inicialmente con el material proveniente de las excavaciones arqueológicas realizadas en la Casa Bodega y Quadra durante la primera temporada, es decir, correspondiente a los ańos 2005 y 2006, a cargo del arqueólogo licenciado Daniel Guerrero. En el año 2009, se logró realizar 


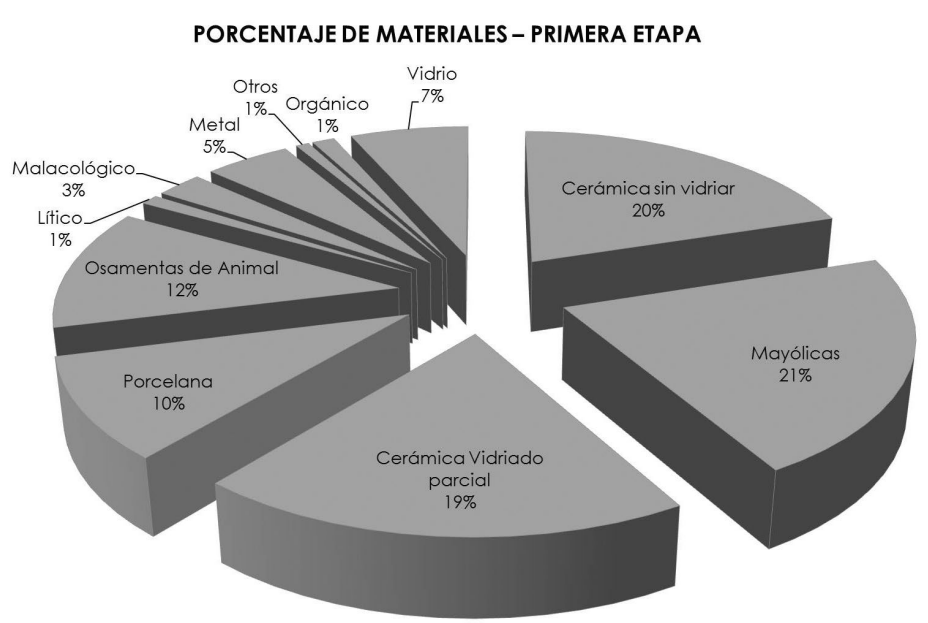

Figura 4. Gráfico de porcentajes de materiales de la Colección Bodega y Quadra, primera temporada y/o etapa 20052006 (Gráfico por M. Fhon).

PORCENTAJE DE MATERIALES - SEGUNDA ETAPA

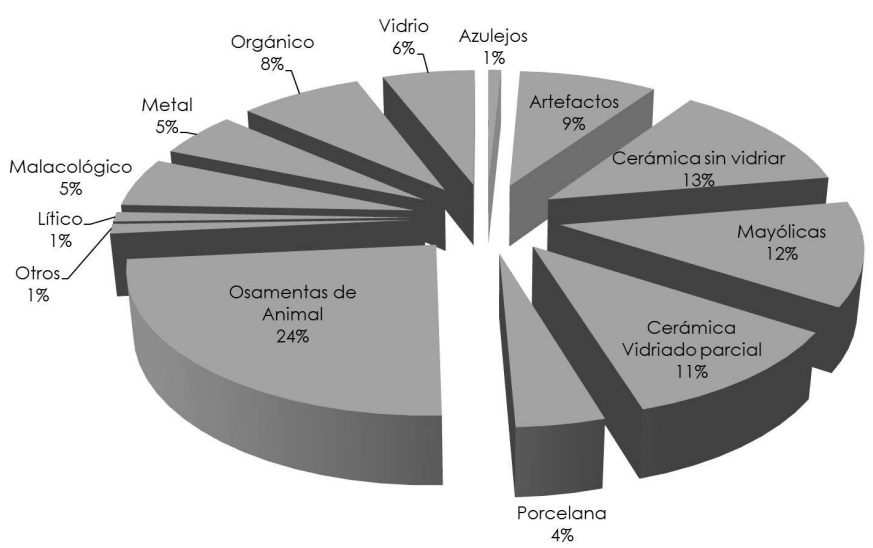

Figura 5. Gráfico de porcentaje de materiales de la Colección Bodega y Quadra, segunda temporada y/o etapa 2010 (Gráfico por M. Fhon).

el inventario total del material arqueológico de los trabajos iniciales en la Casa Bodega y Quadra correspondiente a esta primera etapa. Este material fue encontrado aún para procesar, por lo que se procedió a reubicar, clasificar el material, y dar un orden de registro y almacenaje en cajas, teniendo en cuenta su procedencia y número de registro anterior. Se requirió un mayor esfuerzo en el tratamiento y la recuperación de este material. Los trabajos efectuados tuvieron como fin clasificar los materiales arqueológicos para posteriormente ubicarlos en cajas debidamente inventariados y embolsados; esto se realizó con el objetivo de que sean de fácil identificación con fines museables y para integrarlos a la Colección Bodega y Quadra de la segunda temporada.

El material de la primera temporada (2005-2006) conjuntamente con el material de la segunda temporada (2010) conforman actualmente la Colección Bodega y Quadra y está caracterizado 
principalmente por material cerámico fragmentado, osamentas, material malacológico, artefactos, etc., los cuales se dividen de la siguiente manera:

- Cerámica: Se distinguen varios tipos, entre ellos, porcelana, loza, mayólicas, azulejos, entre otros.

- Vidrio: Está conformado por una diversidad de frascos, botellas y artefactos de vidrio.

- Material óseo: Está compuesto en su totalidad por restos óseos de animales.

- Metales: Está constituido por diversos utensilios de metal, incluidos fragmentos de escoria.

- Artefactos: Se denomina así a los objetos de construcción humana; en este tipo de material, destacan las cuentas.

- Material malacológico: Destacan, entre la colección de hallazgos, los moluscos de las especies: Argopecten purpuratus, Choromitilus chorus, entre otros bivalvos.

- Material lítico: Predominan los artefactos de piedra, como batanes, bases de poste, entre otros.

Al hablar de porcentajes, se puede decir que el material arqueológico procedente de la primera temporada (2005-2006) está conformado en un $21 \%$ de mayólicas, seguido de un $20 \%$ de cerámica sin vidriar, un $19 \%$ de cerámica con vidriado parcial, $12 \%$ de osamentas de animal, $10 \%$ de porcelana, $7 \%$ de vidrio, $5 \%$ metal, $3 \%$ de material malacológico, $1 \%$ lítico, $1 \%$ material orgánico y $1 \%$ otros (Fig. 4).

En la segunda temporada (2010), los materiales arqueológicos están conformados por un $24 \%$ de osamentas de animal, $13 \%$ de cerámicas sin vidriar, $12 \%$ de mayólicas, $11 \%$ de cerámica con vidriado parcial, $9 \%$ de artefactos, $8 \%$ material orgánico, $6 \%$ vidrio, $5 \%$ metal, $5 \%$ material malacológico, $4 \%$ porcelana, $1 \%$ azulejos, $1 \%$ lítico y $1 \%$ de otros (Fig. 5).

\subsection{Las cerámicas}

Las características de las cerámicas encontradas se dividen en cinco tipos: las mayólicas, las cerámicas sin vidriar, cerámicas con vidriado parcial, la porcelana, y la loza.

\subsubsection{Las mayólicas}

Se denomina así al grupo de cerámicas vidriadas en toda su superficie y compuesta de pasta rojiza. Según García, el nombre mayólica usado para este tipo de cerámica proviene del término mayórica o mayorca, que fue muy difundido en Italia (2009 [1877]). En la Casa Bodega y Quadra, se han encontrado diversos estilos, entre los que destacan el estilo panamá polícromo tipo A y B, panamá azul sobre blanco y panamá liso (Long 1967; Goggin 1968; Deagan 1987; Rovira 2001). Las formas más representativas corresponden a platos (Fig. 6).

\subsubsection{Las cerámicas de vidriado parcial}

El estilo más común de este tipo de cerámicas, encontrada en la Casa Bodega y Quadra, corresponde al estilo conocido mayormente en la terminología norteamericana como Green bacin o Green lebrillo (Goggin 1968; Deagan 2002). Se caracteriza por ser una cerámica con vidriado parcial de color verde y sus formas más comunes son del tipo de cerámica utilitaria, entre las que se encuentran los bacines, lebrillos, cántaros, pequeñas botellas, candeleros, entre otros (Fig. 7).

\subsubsection{Las cerámicas sin vidriar}

En la Casa Bodega y Quadra, se ha podido encontrar este tipo de cerámica, el cual se caracteriza por su aspecto simple sin vidriar y sin pintar; a este grupo pertenecen las formas de ollas, jarras, cántaros, botijas, entre otros (Fig. 8). Botijas han sido halladas también en contextos de El Caribe, que han sido denominadas con el término de Olive jar (Goggin 1960). 


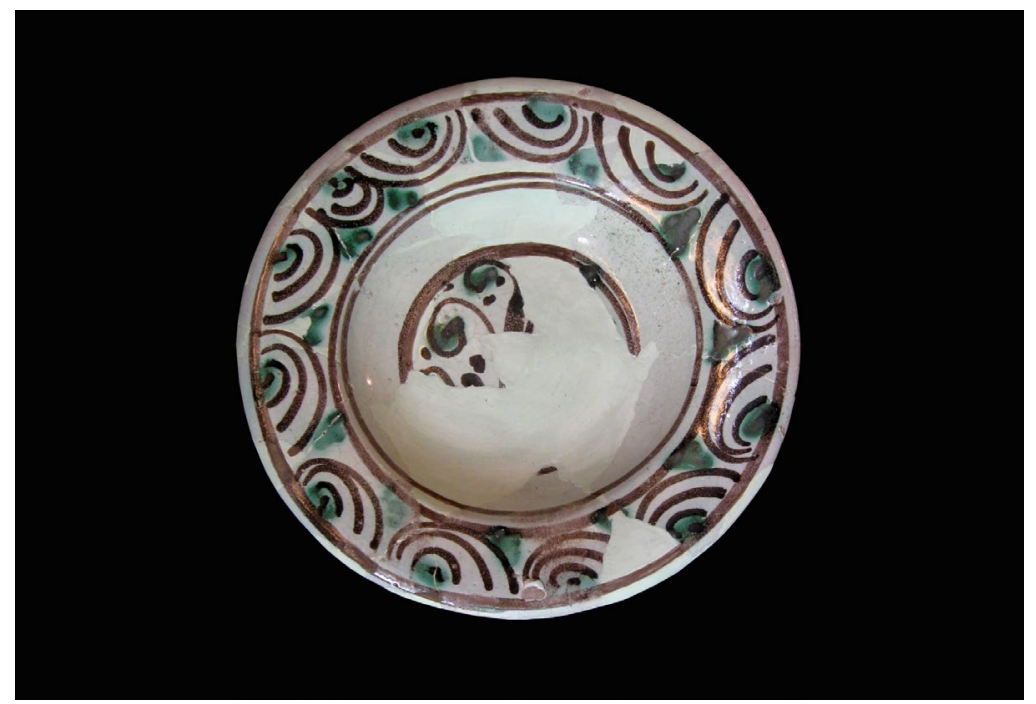

Figura 6. Plato de mayólica de estilo Panamá Polícromo, procedente de las excavaciones arqueológicas en la Casa Bodega y Quadra (Foto por M. Fhon).

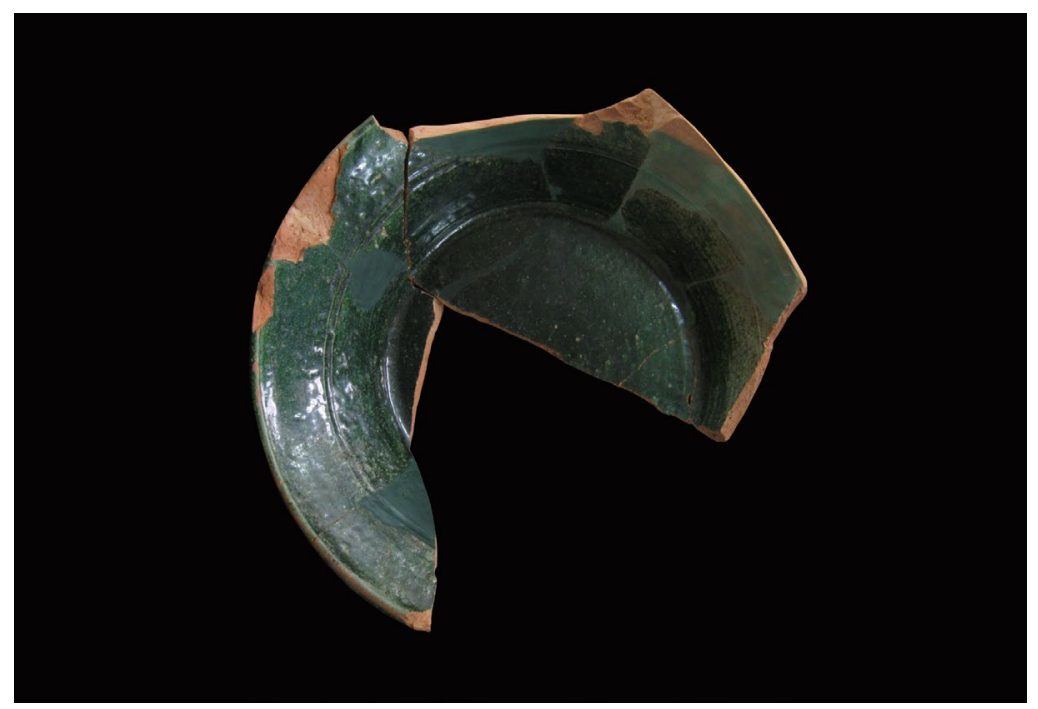

Figura 7. Lebrillo con vidriado parcial de estilo Green bacin o Green lebrillo, hallado en la Casa Bodega y Quadra. (Foto por M. Fhon).

\subsubsection{La porcelana}

Propia del estilo oriental, este tipo de cerámica presenta un mejor tratamiento y delicadeza en la manufactura. En la Casa Bodega y Quadra, destaca el hallazgo de porcelana china, perteneciente a la dinastía Ming (Fhon 2012), que evidencia el comercio con Oriente durante el virreinato del Perú (Fig. 9).

\subsubsection{La loza}

Los hallazgos en la Casa Bodega y Quadra han reportado este tipo de cerámica, específicamente de los estilos loza inglesa impresa por transferencia o pearlware transferd printed (Fig. 10), loza inglesa blanca o pearlware plain, loza inglesa polícroma pintada a mano tardío o pearlware, hand painted 


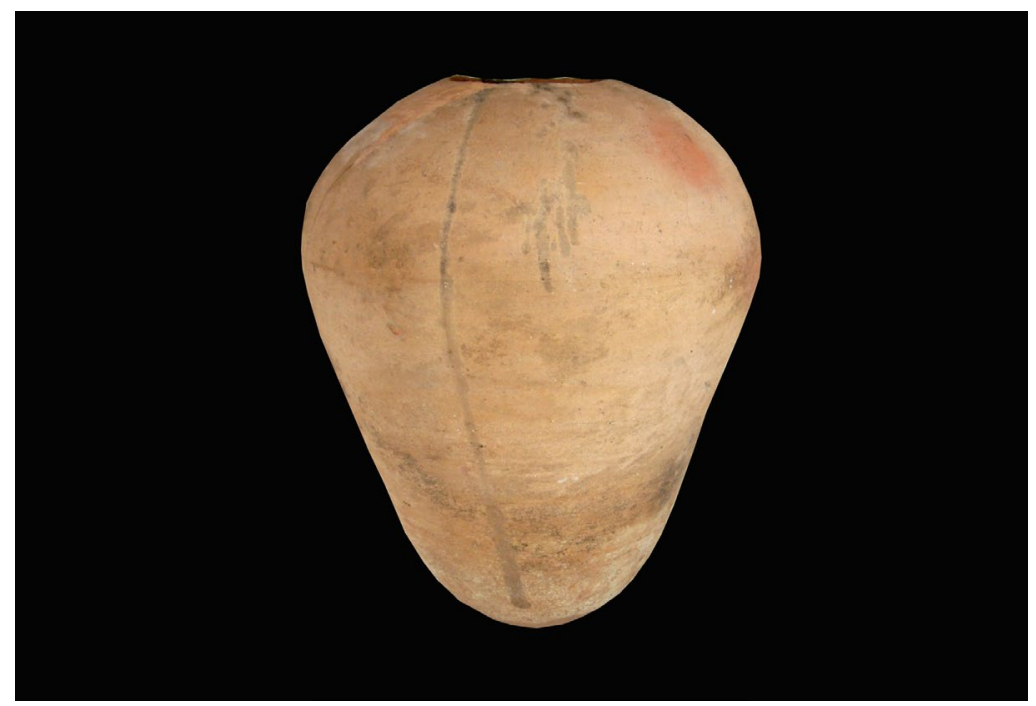

Figura 8. Botija encontrada en la Casa Bodega y Quadra (Foto por M. Fhon).

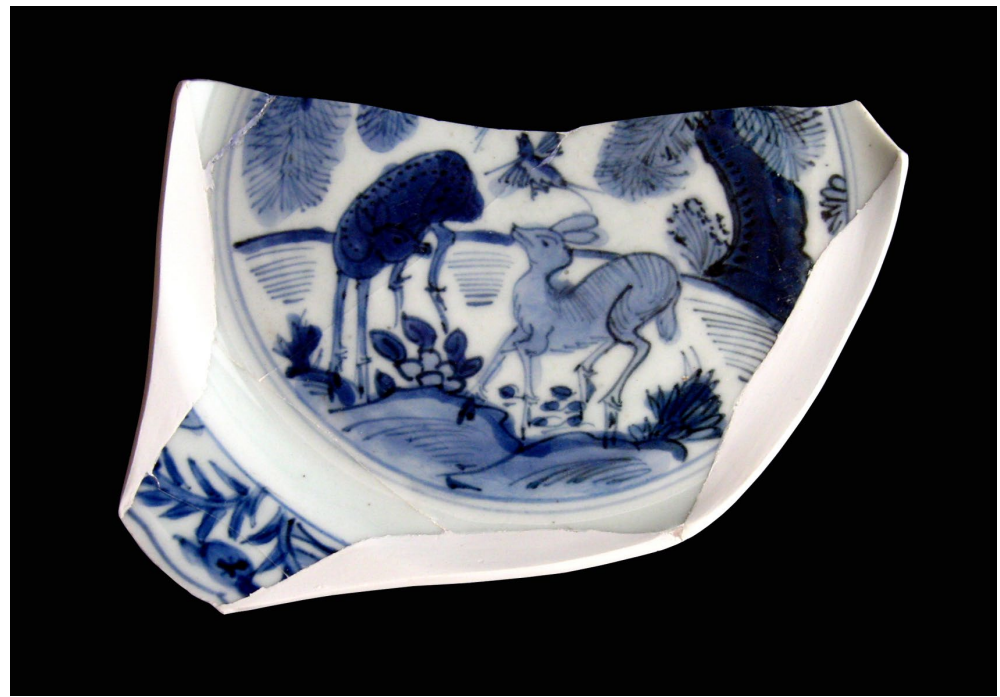

Figura 9. Plato de Porcelana China - azul sobre blanco_, dinastía Ming, descubierta en la Casa Bodega y Quadra (Foto por M. Fhon).

polychrome, late, y el estilo de cerámica gress o stoneware, de las características bristol glaze ginger beer bottle y stoneware, brown rhenish.

\section{Los rellenos constructivos}

Como se mencionó, el área correspondiente a la parte baja de la casa estuvo cubierta por una gruesa capa de relleno integrada por fragmentos de diversos objetos. Si bien es cierto la mentalidad virreinal concebía que los terrenos posteriores y baldíos dentro de la casa fueran destinados como botaderos, los rellenos a los que hacemos mención fueron utilizados apropiadamente para nivelar 


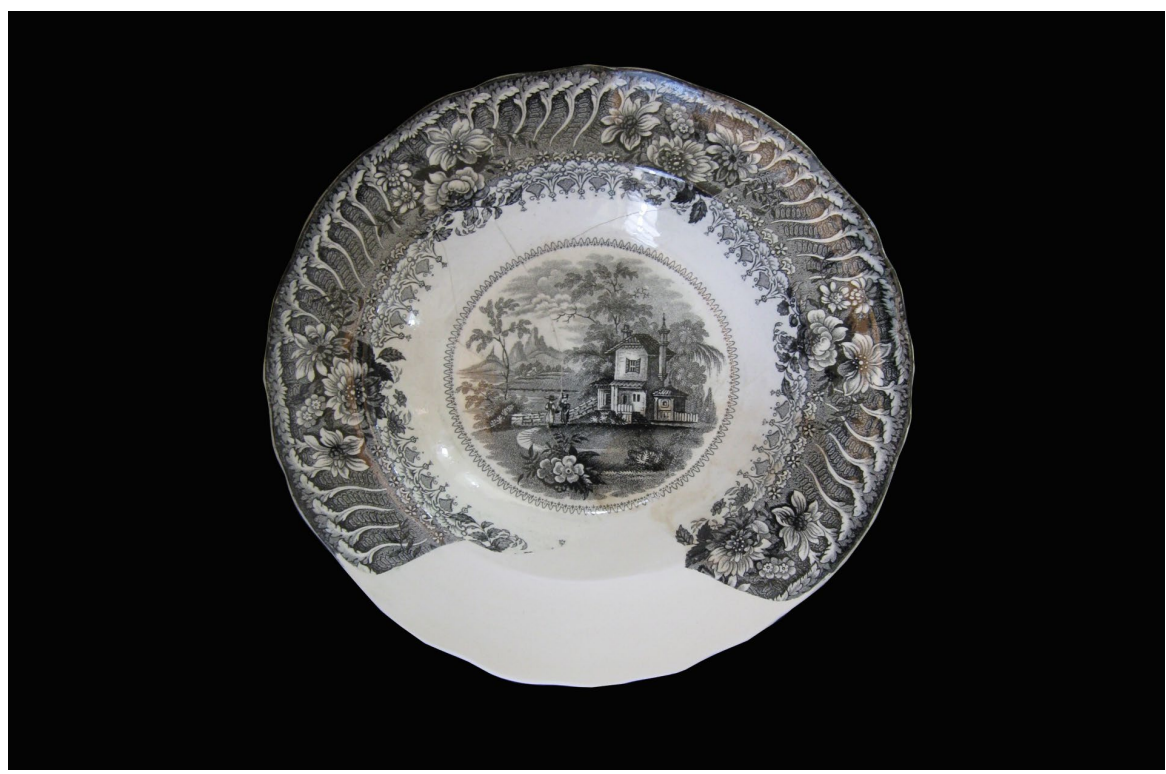

Figura 10. Plato de Loza inglesa con impresión por transferencia, hallado en la Casa Bodega y Quadra (Foto por M. Fhon).

el terreno y bien podrían denominarse rellenos constructivos (Fig. 11). Este tema no ha recibido la atención necesaria de parte de los arqueólogos; no obstante, su estudio podría revelar valiosa información. Tal como sugiere Mogrovejo, el estudio de basurales, canales y pozos sépticos permitiría obtener evidencia sobre los desechos de aquella época (1998: 26-30). Entonces, no solo se encuentra información importante procedente de los vestigios arquitectónicos, más esclarecedor resulta el análisis del material cultural extraído de estos rellenos.

Si observamos a detalle las unidades de excavación se entrevé en algunos recintos hasta un máximo de 10 capas, en las que los estratos superiores están conformados por tierra semisuelta, con evidencia de ceniza, fragmentos de ladrillos, loza europea y cerámica, presencia de material orgánico y malacológico. En las capas inferiores, también, se condensa material cerámico de diferentes tradiciones que abarcan vidriados, porcelana china, botijas, etc.

Podemos sugerir que las capas de relleno habrían sido acumuladas desde el siglo XVIII y continuado durante las primeras décadas del siglo XIX. Los desechos de escoria y artefactos acabados permiten deducir la existencia próxima de una fundición o un taller de metal. Del mismo modo, cabe resaltar que las capas inferiores del pasaje de Tajamar contienen una considerable cantidad de cuentas y joyería. Es posible que estas joyas fueran derivadas a ese depósito luego de la limpieza de los talleres de manufactura y mezcladas con otros elementos. Ahora bien, se ha registrado gran concentración de óxido ferroso que ha formado masas compactas de tierra y piedras junto al material cultural. Por ello, es más interesante sugerir que dichos talleres habrían colapsado por alguna razón, posiblemente, un gran sismo que evitó su recuperación de entre los escombros y, por esa razón, habrían terminado junto a los desechos de fundición. Más aún, se han localizado otros elementos como cristales, dijes y aretes de preciosos acabados que presentan evidencias de haber sido usados y hasta deteriorados, lo cual refuerza esta hipótesis.

\section{Las estructuras arquitectónicas bajo las capas de relleno}

Como resultado de las excavaciones en esta área, se pudo afirmar que, durante el período virreinal, hubo una recurrencia a distintos elementos y técnicas constructivas; con ello, se pudo establecer una secuencia más clara de la ocupación. A partir de las observaciones de campo, se propuso una 


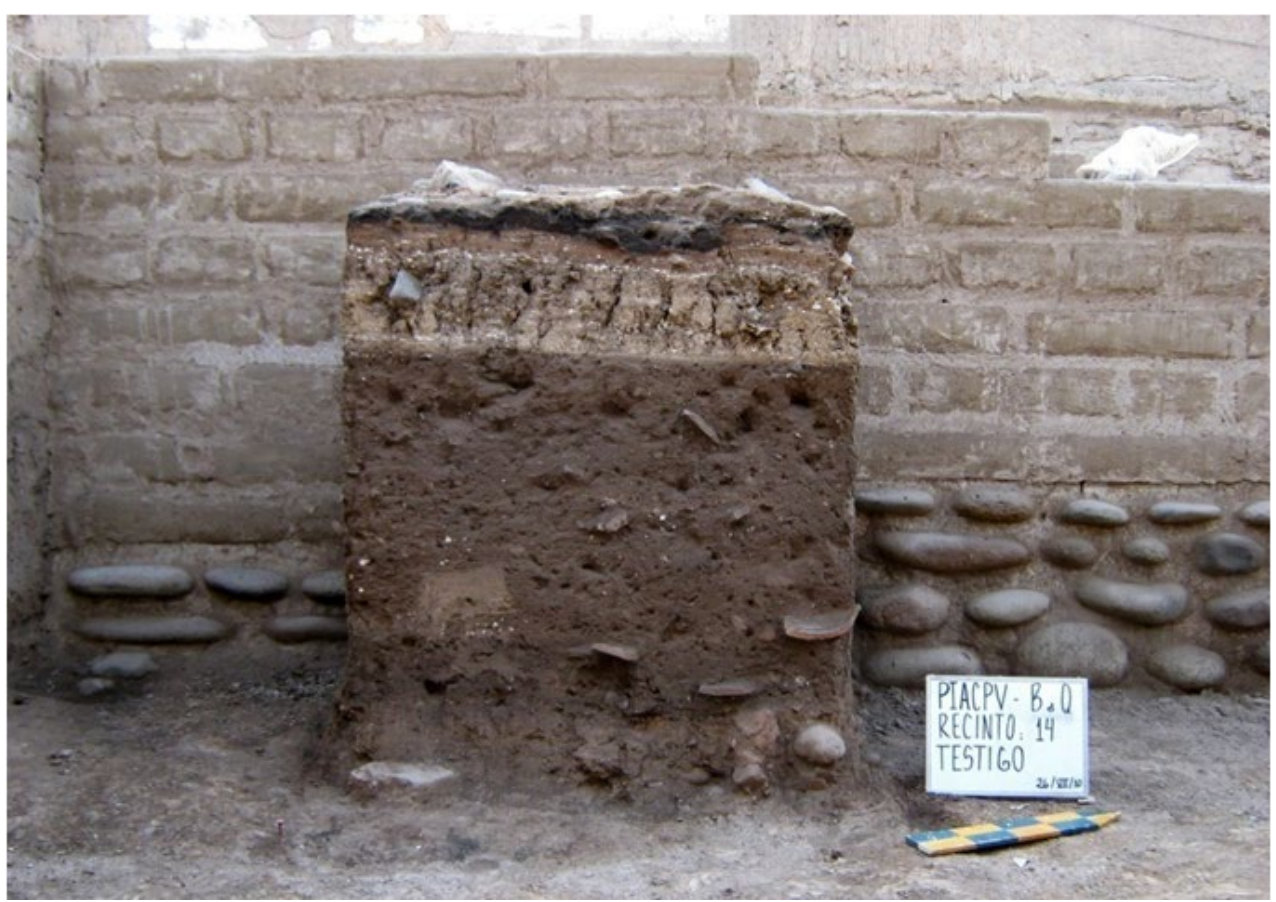

Figura 11. Vista Oeste del testigo de relleno en el Recinto 14, Plataforma 02 (Foto por P.I.A.C.P.V. Casa Bodega y Quadra-Municipalidad Metropolitana de Lima).

secuencia constructiva que privilegia el análisis de los adosamientos y juntura de muros terminados a muros preexistentes, los cambios de eje, la superposición, la técnica constructiva asociada al acabado o revestimiento de la construcción y a la lógica de circulación. Por ello, el proceso de ocupación arquitectónica de la casa materia de análisis estaría integrado por cinco fases (Fig. 12).

La primera fase está definida por estructuras con sobre cimiento de piedra canteada y mortero de cal, con muros de adobón y mortero de barro ubicados en el extremo sur de la casa, los vanos y ventanas presentan pie derecho de ladrillos tipo pastelero. Al parecer, los muros más antiguos sirvieron para hacer una estructura de contención, la cual define el límite a desnivel de la ladera del río en donde se asientan dichas estructuras que conforman los recintos 10, 8, 20, 5 y 13. En este sentido, las construcciones primigenias tienen una forma en "L», que posiblemente rodean el pozo de agua. Cabe destacar la importancia de este pozo durante la época virreinal, ya que las bocatomas prehispánicas destinadas al riego del valle fueron reutilizadas para el abastecimiento constante de agua fresca. Si bien aún no se ha determinado si el pozo estuvo ubicado a extramuros de la casa, podría sugerirse que fue un espacio público y abierto debido a la ausencia de techumbre, y era común la implementación de pilas para proveer de este líquido a los habitantes de esta ciudad. No obstante, el cronista Cieza de León afirma en referencia a la ciudad de Lima lo siguiente: «Y por todas las más de las casas passan acequias, que es no poco contento: del agua dellas se siruen, y riegan sus huertas y jardines, que son muchos, frescos y deleytosos» (1995 [1553]: 212).

La siguiente fase constructiva se caracteriza por ser muy similar a las técnicas constructivas anteriores; sin embargo, los muros ostentan un ancho menor muy notorio y se adosan a las estructuras de la fase anterior. Los muros de los recintos 6, 7, 11 y 15 corresponden a esta etapa. Se observa también que, en el sobre cimiento, se incluyen materiales como cantos rodados y ladrillos tipo pastelero, incluso algunos reutilizados.

La tercera fase corresponde a una ampliación de los recintos del lado este de la primera fase y hacia el lado norte de los recintos del área central. Los muros presentan sobre cimiento de 


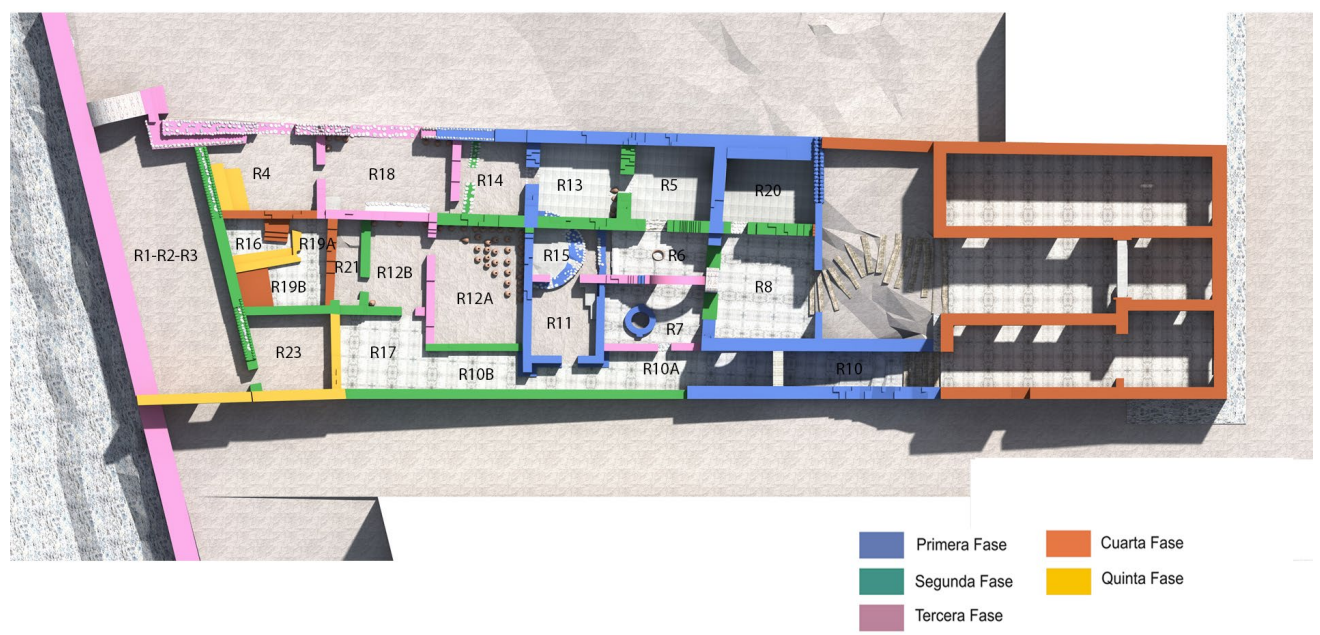

Figura 12. Fases Constructivas del sector Norte de la casa Bodega y Quadra (3D elaborado por la Municipalidad Metropolitana de Lima - EMILIMA S.A.).

canto rodado y algunos «pie derecho», elementos arquitectónicos muy útiles para dar refuerzo a los ventanales, vanos de acceso y arcos, elaborados con ladrillo pastelero, piedra canteada y cal. Los recintos correspondientes a esta fase son el 11, 15, 12A, 14 y 18. Estos dos últimos recintos presentan improntas de postes, correspondientes probablemente a techos de ramadas, los mismos que en su entorno contienen evidencias que sugieren su uso como corrales de animales ${ }^{2}$.

La cuarta fase guarda relación con la última ampliación hacia el lado norte y presenta un ligero movimiento del eje original de la casa. Se ha observado la construcción de algunos recintos y la remodelación de otros; asimismo, los muros mantienen el tipo de manufactura, es decir, el sobre cimiento de cantos rodados y muros de adobes. En esta fase, se realizaron las últimas remodelaciones con muros que dividen el recinto 19 en compartimientos más pequeños. Ejemplos de esta fase se encuentran en los recintos 4, 17, 19 y 23.

Finalmente, la quinta fase en la secuencia constructiva corresponde al período republicano. Lamentablemente, solo han permanecido los cimientos ubicados sobre los recintos 5, 13, 20, paralelo al muro del lado este (Conjunto Habitacional La Muralla). Forman parte de esta fase los recintos 9 y 21.

De igual manera, se logró definir distintos tipos de arcos elaborados con adobe y ladrillo de aproximadamente 53 por 24 por 12 centímetros y 29 por 14 por 5 centímetros respectivamente, una diversidad de técnicas en la construcción de los muros en la que prevalece el uso y la mezcla de elementos como la piedra canteada de gran tamańo y piedra de canto rodado. De este modo, se logra una fusión de componentes constructivos que se reflejan en algunos paramentos que presentan, en la base, piedra canteada y adobe en la parte superior. En otros casos, se encuentran muros de piedra canteada con fragmentos de ladrillo y piedra en la argamasa, muros de adobe con base de canto rodado y barro, y finalmente muros de ladrillo con canto rodado. La presencia de muros con cimientos de piedra de procedencia de cantera, los mismos que presentan la superficie plana expuesta hacia la cara del muro y unidas algunas veces con mortero de barro y otras con cal y canto, se ubican bajo las bases de los muros de adobe. Otros muros de características diferentes son aquellos en los que todo el paramento es construido con piedra de cantera y que se evidencian en solo dos recintos.

Las excavaciones también revelaron la existencia de un pasaje que iba en paralelo al contrafuerte o tajamar (Fhon 2014), creado para resistir las variaciones de caudal y posibles desbordes del río Rímac. Jorge Bernales (1972) menciona que la edificación de estos muros de contención se 
hacía seguidamente a la fundación de la ciudad y su uso continuó hasta el siglo XVII. ${ }^{3}$ La ejecución del tajamar del lado del convento franciscano es atribuida a Bernardino de Tejada (Bernales 1972: 128). Debemos señalar enfáticamente que las estructuras más tardías ubicadas sobre el relleno que cubría el pasaje de tajamar solo se habrían construido durante la época republicana al realizarse una ampliación de la casa hacia el norte, lo cual estaba delimitado por el muro que servía como contrafuerte, pues durante el virreinato esa zona se encontraba fuera del perímetro de la casa donde existía un pasaje externo.

\section{El terremoto de Lima de 1746}

La ciudad de Lima ha sufrido una serie de sismos de distintas magnitudes; estos eventos motivaron a sus habitantes a reconstruir sus viviendas cada vez que se enfrentaban a este tipo de desastres. Durante el siglo XVIII, uno de los mayores movimientos telúricos que causó graves daños a la ciudad de Lima fue el terremoto de 1746; se calcula que tuvo una magnitud de 8,4 grados, lo cual es aún más fuerte que aquel que afectó a la capital en 1687.

El estado como quedó la casa que hoy conocemos como Casa Bodega y Quadra, en ese entonces perteneciente a la familia Altolaguirre, a raíz del terremoto de 1746 , fue determinante para restarle valor al predio. A partir de ello, fue vendida dos ańos después de ocurrido el fuerte movimiento telúrico a don Thomas de la Bodega y Quadra, lo cual queda demostrado en el protocolo notarial de Bernardino Méndez de Zúñiga del 19 de septiembre de 1748, denominado «Venta de un Solar a D. Thomas de la Bodega y Quadra», el mismo que incluye una pequeña mensura realizada por Pedro Ramírez, maestro mayor de fábricas y alarife. El mismo describe lo siguiente: «[...] y así mismo reconocí todo lo que quedo en pie con el gran terremoto que hubo el año de cuarenta y seis fueron algunas paredes pero esta están demolidas como también alguna puerta bien maltratada, los techos reconocí están inservibles [...], y siendo así que toda la casa esta quasi echa solar lo aprecio y taso [...] en catorce mil quinientos quarenta y quatro pesos reales y para que conste lo firme en veinte y ocho de mayo de mil setecientos quarenta y ocho» ${ }^{4}$.

Cabe destacar en esta descripción la presencia aún de estructuras que quedaron en pie después del terremoto de 1746. Las paredes demolidas a las que hace mención el alarife Ramírez habrían generado todo el material de relleno constructivo encontrado posteriormente en las excavaciones arqueológicas en la Plataforma 2 de la Casa Bodega y Quadra. Se pudo encontrar, además, evidencias de remodelaciones clausura de espacios, restos de antiguos pies derecho de arcos en piedra y ladrillo; lo más importante de resaltar son las grandes concentraciones de rellenos que contenían escombros, que sirven como material para nivelar la sección de la ladera con la parte elevada de la casa.

\section{Períodos de ocupación}

Los conceptos de cambio y permanencia pueden aplicarse perfectamente a la Casa Bodega y Quadra, puesto que ha tenido una ocupación sucesiva con el paso de los siglos. Por un lado, la arquitectura de la casa fue adaptándose continuamente a las necesidades de sus habitantes. Prueba de ello son las sucesivas remodelaciones en su arquitectura y, por otro, porque ha resistido a los innumerables procesos y transformaciones - humanas y naturales - sucedidos en cada período, testigos del cambio del imaginario social y cultural. Precisamente, ahora abordaremos estas ocupaciones y las relacionaremos con la evolución de la ciudad.

La más temprana ocupación que se puede rastrear, sobre la base del análisis del material arqueológico, dataría del siglo XVII por la fusión de formas cerámicas de tradición nativa e hispana, y los burdos acabados de la cerámica conocida como green bacin. Se puede añadir el cambio en las técnicas de manufactura, que pasa del moldeado al uso del torno, y la adopción de nuevas técnicas de decoración o enlucido (vidriado). A la abundancia de fragmentos de cerámica virreinal 
se suma la presencia de una cantidad considerable de osamenta animal, atribuida posiblemente a la ocupación de los primeros mercados o mataderos en esta área. Durán menciona que el primer matadero de la ciudad se asentaba en lo que hoy es la estación de ferrocarril de Desamparados, junto a la alhóndiga (1994: 90). Hacia fines del siglo XVI, el Cabildo limeño decidió trasladar la carnicería al barrio de San Lázaro; de este modo, la alejó del centro de la ciudad como una medida de salubridad. No obstante, durante los siglos XVII y XVIII, la carnicería aún se ubicaba en los alrededores de la Casa Bodega y Quadra 5 .

De acuerdo a las fuentes históricas, para el siglo XVII, la ocupación documentada refiere a la propiedad de la casa en manos de Manuel Pedro De la Cueva, quien vende la propiedad a don Francisco Martínez de Saavedra. Posteriormente, en un remate público, dichos bienes fueron adquiridos por Felipe de Altoaguirre y su esposa María Manuela de Ylarduy, hacia el siglo XVIII'. Gracias a las escrituras de compra y venta, sabemos que Dońa Manuela Ylarduy traspasa la casa a don Thomas de la Bodega y Quadra. Para esto, la casa ya deteriorada por consecuencias del terremoto de 1746 fue rematada a precio de solar y valorizada en 14.544 de a cinco reales, según la tasación realizada por Pedro Ramírez en el mismo año ${ }^{7}$. De acuerdo con las evidencias históricas presentadas y con la evidencia arqueológica, todo indicaría que las estructuras habrían ocupado la ladera del río de forma gradual, hasta alcanzar el límite norte actual de la casa Bodega y Quadra. Según Hampe, la casa Bodega y Quadra corresponde al virreinato de mediados del siglo XVIII, y estaba conformada por dos plantas en su porción delantera y una larga prolongación en galerías subterráneas sobre el lecho del río Rímac (Hampe 2008: 3).

A la luz del protocolo notarial de venta del solar, sabemos que Don Thomas realiza una serie de remodelaciones en las que alude que «habré gastado en la fábrica de dicha casa veinte mil pesos más o menos por tenerla fabricada toda con varias bodegas de entre suelo». Efectivamente, en el área de la segunda plataforma (sector norte), se hallaron estructuras «entre suelos», acompañadas de botijas y de bordes con sellos. Asimismo, se hace hincapié en las remodelaciones que también fueron reconocidas durante nuestras excavaciones. En el extremo sur de la ladera, ya habrían existido algunos restos de ocupaciones anteriores; sobre ellos, se adaptaron las áreas para depósitos y bodegas, que se reflejan in situ, en los que algunos paramentos revelan el cierre y la apertura de algunos accesos, así como la alteración y redefinición de los espacios en concordancia con las necesidades del nuevo propietario.

Al respecto, es importante rescatar el papel desempeñado por don Thomas de la Bodega y Quadra dentro de las redes comerciales establecidas en la ciudad de Lima a mediados del siglo XVIII. Si bien es cierto don Thomas era natural de Vizcaya (España), había contraído nupcias con una criolla, Doña Francisca de Mollinedo y Lozada Agüero, y gozaba de alianzas familiares establecidas por sus antepasados. La cohesión y los lazos familiares eran tan importantes que debían transferirse a los negocios para fortalecer al grupo. Por ello, no es de extrañar que don Thomas formara parte del círculo familiar de José Antonio de Lavalle y Cortés, próspero comerciante criollo (Mazzeo 1994: 75-79). Por otro lado, Thomas de la Bodega y Quadra fue prior del Consulado entre los años 1762 y 1764, dueños de varios navíos — como San Leonardo y Oriflama-y representó a los Cinco Gremios Mayores de Madrid (Turiso 2002: 294).

Como se puede observar, inicialmente el espacio ubicado por la actual casa Bodega y Quadra habría estado conformado por espacios comunes, relacionados con la primera carnicería y con el rastro de San Francisco, de confluencia para los habitantes de esta ciudad; recién a partir del siglo XVII se puede afirmar que dichas áreas fueron modificadas en espacios domésticos y residenciales con una distribución arquitectónica que subsiste hasta nuestros días.

Durante el siglo XVIII, como consecuencia del terremoto de 1746, gran parte de los escombros fueron a nivelar un gran porcentaje de la ladera. Las consecuencias producidas por dicho terremoto fueron aprovechadas por don Thomas de la Bodega y Quadra, lo cual le permitió acceder a un espacio privilegiado tras adquirir el predio de don Felipe Altolaguirre, al quedar este deteriorada y al restarse su valor original. Un gran trabajo de remodelación que tuvo que asumir 
el nuevo propietario don Thomas de la Bodega y Quadra al comprar la casa dos años después de este trágico suceso ocurrido en Lima.

Más adelante, durante el siglo XIX, la Casa Bodega y Quadra vuelve a transformarse, debido a que se llevaron a cabo variaciones de forma y función, que terminaron de sellar los rellenos ya existentes. El traslado del rastro, ubicado en los alrededores de la Casa Bodega y Quadra, fue uno de los momentos clave que permitió realizar una limpieza de los desechos que habían dejado las actividades del rastro; por ello, los restos habrían sido utilizados para terminar de rellenar los desniveles propios de la ladera del río.

Como se ha señalado, los cambios se fueron realizando de acuerdo con los sucesos que acontecieron en la ciudad y que determinaron su morfología; los siglos XVII y XVIII fueron los períodos en los que los espacios se alteraron aún más, como consecuencia de los grandes terremotos que tuvo la ciudad de Lima y por los cuales se generó una gran cantidad de escombros. La nivelación con desechos y escombros sobre las estructuras de la parte baja de la Casa Bodega y Quadra, y el pasaje entre la casa y el muro de tajamar crearon una plataforma artificial de material de relleno existente con la finalidad de nivelar y ampliar los límites de la casa hacia el lado norte hasta alcanzar y cubrir, incluso, el contrafuerte del río Rímac.

\section{Conclusiones}

Sobre la base de las investigaciones arqueológicas, se pudo concluir que las estructuras ubicadas a cuatro metros de profundidad, a diferencia del sector sur de la casa, se asentaron sobre la ladera del río, por lo que las construcciones se adecuaron a la topografía del terreno. Esto se pudo verificar en las excavaciones realizadas en áreas correspondientes al límite de la ladera, lo cual evidenció ausencia de arquitectura y presencia de material aluvial. Esto indicaría que la casa inicialmente presentaba un área construida a dos niveles como consecuencia probablemente del crecimiento y la expansión urbana de la ciudad, al ocupar también terrenos que incluían áreas de ladera de río.

La Casa Bodega y Quadra, según los resultados de las excavaciones, presentó claramente en su arquitectura el empleo de diferentes técnicas constructivas. Esto podría ser un indicador de que el área fue construida en diversos períodos de ocupación y que el espacio estuvo sujeto a remodelaciones constantes. Muchos muros fueron reutilizados por las distintas ocupaciones de la casa. Según la evidencia arqueológica e histórica, la manzana que hoy ocupa el área de investigación estuvo sujeta a una continua transformación de forma y función del espacio.

El enterramiento de dichas estructuras habría ocurrido como consecuencia del aprovechamiento de grandes concentraciones de escombros y desechos producto de los dos grandes terremotos ocurridos en Lima, durante los siglos XVII y XVIII; estos se emplearon como relleno constructivo para nivelar depresiones de terreno y parte de la ladera del río Rímac. Debido a ello, las estructuras arquitectónicas que se encontraban a desnivel sobre la ladera del río en este sector de la casa fueron enterradas con diversas capas de relleno buscando nivelar este sector norte con el sector sur de ingreso a la casa; de esta manera, se cubría toda evidencia arquitectónica existente. Nuevas estructuras correspondientes a períodos más tardíos se edificaron sobre esta plataforma artificial de material de relleno.

El estudio y el análisis detallado de las evidencias materiales encontradas en estos contextos nos permitirán posteriormente ampliar nuestro conocimiento sobre la sociedad virreinal y republicana; de igual modo, es necesario que varias disciplinas confluyan y puedan compartir métodos de investigación que permitan dilucidar esta habitabilidad a lo largo de sus ocupaciones. La arqueología, la historia y la arquitectura se convierten en los eslabones primordiales para efectuar un estudio a profundidad. 


\section{Agradecimientos}

La presente investigación es el resultado del Proyecto Arqueológico, Conservación y Puesta en Valor de la Casa Bodega y Quadra, patrocinada por Emilima S.A., Municipalidad Metropolitana de Lima.

\section{Notas}

${ }^{1}$ Los trabajos arqueológicos iniciados por Guerrero (temporadas 2005-2006) inciden en la existencia de estructuras que conformaban recintos del período virreinal, los cuales presentaban diversas técnicas y elementos constructivos. Guerrero y Merino (2006), al referirse a los hallazgos describen: «[...] al inicio de nuestros trabajos hallamos las estructuras subterráneas... De todo el sector investigado [...] se hallaron patios y galerías techadas cuya altura original se hallaba intacta, la parte central estaba a tres metros bajo el nivel original de la superficie... [destaca por su presencia de] estructuras de adobe y ladrillo con arquerías, algunas de las cuales presentan cubiertas de madera». cf. Guerrero y Merino.

${ }^{2}$ La RAE define el término doméstico como perteneciente o relativo a la casa u hogar. En el presente trabajo, se refiere a los asentamientos y estructuras que permiten reconocer los comportamientos y actividades cotidianas en base al análisis de los objetos y de la cultura material ( $c f$. Allison 1999: 12). Para una redefinición del término household puede verse el artículo de Rani Alexander en ese volumen.

${ }^{3}$ Para 1689, el cabildo limeño buscó resolver el problema del tajamar de Nuestra Señora de la Cabeza. Para ello, se ordenó que el mayordomo y capellán de la capilla acumulen tierra y basura. Se propuso notificar a los dueños de recuas para que efectúen dicho trabajo y trasladen a ese paraje toda la tierra y basura que encuentren (AHML. Libro de Cabildos 32, fs. 154 v.).

${ }^{4}$ AGN, Protocolos Notariales, Bernardino Méndez, prot. 715 (1748).

${ }^{5}$ AGN, Protocolos Notariales, Bernardino Méndez, prot. 715 (1748).

${ }^{6}$ AGN, Protocolos Notariales, Bernardino Méndez, prot. 715 (1748). Fs. 288 v.

${ }^{7}$ La tasación realizada el 28 de mayo de 1748 evidencia la situación del solar. El inmueble, de por sí, estaba en pésimo estado, mantenía unos techos apolillados que, luego del terremoto de 1746 quedaron inservibles. Las estructuras quedaron gravemente dañadas; así, se infiere que el terreno había sido devaluado (AGN, Protocolos notariales, Bernardino Méndez, prot. 715 (1748) Fs. 291 v.).

${ }^{8}$ AGN, Protocolos Notariales, Francisco de Luque, prot. 604 (1763). Fs. 193-201.

\section{FUENTES MANUSCRITAS}

Archivo Histórico de la Municipalidad de Lima (AHML). Lima

1689 Libro de Cabildos 32, fs. 154 v.

Archivo General de la Nación (AGN). Lima

1748 Protocolos Notariales, Bernardino Méndez, prot. 715.

1763 Protocolos Notariales, Francisco Luque, prot. 604. 


\section{REFERENCIAS}

Allison, P.

1999 The archaeology of household activities, Routledge, London. https://doi.org/10.4324/9780203014929

Arrieta, A., C. Arellano, A. Castañeda y J. Polo

1974- Primeros hallazgos en Huaca Casa Rosada (loza, vidrio, cerámica vidriada) asociados al trabajo en el

1975 Archivo Histórico Nacional, Boletín del Seminario de Arqueología 15-16, 159-166.

Bernales Ballesteros, J.

1972 Lima, la ciudad y sus monumentos, Escuela de Estudios Hispano-Americanos de Sevilla, Sevilla.

Cárdenas, $\mathrm{M}$.

1973 Cerámica de transición. Huaca Palomino, Boletín del Seminario de Arqueología 14, 30-34.

Cieza de León, P. de

1995 Crónica del Perú. Primera parte, 3a ed., Fondo Editorial de la Pontificia Universidad Católica del Perú/

[1553] Academia Nacional de Historia, Lima.

Deagan, K.

1987 Artifacts of the Spanish colonies of Florida and the Caribbean 1500 - 1800, Volume 1: Ceramics, glassware, and beads, Smithsonian Institution Press, Washington, D.C.

2002 Artifacts of the Spanish colonies of Florida and the Caribbean 1500 - 1800. Volume 2: Portable personal possessions, Smithsonian Institution Press, Washington/Londres.

Durán Montero, M. A.

1994 Lima en el siglo XVII. Arquitectura, urbanismo y vida cotidiana, Diputación Provincial de Sevilla, Sevilla.

Fhon Bazán, M.

2012 El comercio con China a través del desentierro de menaje colonial (Casa Bodega y Quadra, Siglos XVI-XVIII), en: R. Chuhue, L. J. Na y A. Coello (comps.), La inmigración china al Perú: Arqueología, historia y sociedad, 23-38, Editorial Universitaria, Instituto Confucio/ Universidad Ricardo Palma, Lima.

2014 Arcos y estructuras subterráneas de época virreinal en la Casa Bodega y Quadra, en: R. Chuhue y P. Van Dalen (eds.), Lima subterránea, arqueología histórica: Criptas, bóvedas, canales virreinales y republicanos, 123-134, Fondo Editorial de la UNMSM, Lima.

Flores, I., R. García y L. Huertas

1981 Investigación arqueológica. Histórica de la Casa Osambela (o De Oquendo), Lima, Centro de Investigación y Restauración de Bienes Monumentales, Instituto Nacional de Cultura, Lima.

García López, D. M.

2009 Manual completo de artes cerámicas o fabricación de objetos de tierras cocidas en todas sus aplicaciones, Tomo

[1877] I, Librería de Cuesta/ Editorial Maxtor, Madrid/Valladolid.

Goggin, J.

1960 The Spanish olive jar: An introductory study, Yale University Publications in Anthropology $\mathrm{N}^{\circ}$ 62, New Haven.

1968 Spanish majolica in the New World, Yale University Publications in Anthropology, $\mathrm{N}^{\circ} 72$, Yale University Press, New Haven.

Guerrero, D. y G. Merino

2006 Informe final de investigación arqueológica Casa Bodega y Cuadra y la Muralla de Lima, Instituto Nacional de Cultura/Emilima, Lima.

Hampe Martínez, T.

2008 La casa natal de Bodega y Quadra en Lima, Chasqui, Boletin Cultural del Ministerio de Relaciones Exteriores $6(13)$.

Long, G. A.

1967 Archaeological investigations at Panamá la Vieja, tesis de maestría, Departmento de Antropología, University of Florida, Gainesville.

Mazzeo, C. A.

1994 El comercio libre en el Perú: Las estrategias de un comerciante criollo, José Antonio de Lavalle y Cortés, 17771815, Fondo Editorial de la Pontificia Universidad Católica del Perú, Lima. 
Mogrovejo Rosales, J.

1998 Arqueología urbana de evidencias coloniales en la ciudad de Lima, Cuadernos de Investigación 2/1996, Instituto Riva-Agüero 173, Pontificia Universidad Católica del Perú/Instituto Riva-Agüero, Lima.

Rovira, B.

2001 Actualizando el pasado. El Proyecto Arqueológico Panamá Viejo, Arqueología de Panamá La Vieja, 1-11.

San Cristóbal, A.

1992 Lima: estudios de la arquitectura virreinal, Epígrafe Editores, Lima.

Turiso Sebastián, J.

2002 Comerciantes españoles en la Lima borbónica: anatomía de una élite de poder (1701-1761), Universidad de Valladolid, Secretariado de Publicaciones e Intercambio Editorial/Pontificia Universidad Católica del Perú, Instituto Riva-Agüero, Valladolid/Lima. 